\title{
Self-Reported Harassment and Bullying in Australian Universities: Explaining differences between Regional, Metropolitan and Elite Institutions
}

\author{
Timothy C. Skinner, David Peetz, Glenda Strachan, Gillian Whitehouse, Janis \\ Bailey \& Kaye Broadbent
}

\begin{abstract}
We analyse data from the largest survey of university staff in Australia to determine whether bullying and harassment are more common in Regional than Metropolitan and Go8 universities, and to what extent any differences could be attributed to other factors. While professional staff showed no difference in harassment rates between Regional and Metropolitan and Go8 universities, academic staff at Regional universities reported significantly higher levels of harassment. This probably reflected the labour market and resource context of Regional universities. Binary logistic regression indicated that a perceived lack of support for professional development partially explained the effect of Regional status on differences in rates of harassment/bullying across university types. Markers of organisational culture only partially account for differences in rates of harassment/bullying between university types.
\end{abstract}

Published as: Timothy C. Skinner, David Peetz, Glenda Strachan, Gillian Whitehouse, Janis Bailey \& Kaye Broadbent, 'Self-Reported Harassment and Bullying in Australian Universities: Explaining differences between Regional, Metropolitan and Elite Institutions', Journal of Higher Education Policy and Management, 37(5), October 2015, 558-571.

Keywords: bullying, harassment, regional, prejudice, development

\section{Contact details:}

Timothy C. Skinner (Corresponding Author)

Psychological and Clinical Sciences,

Charles Darwin University,

Ellengowie Drive,

Cassuarina, Darwin, 0909.

Tel: 0889466408

Email: timothy.skinner@cdu.edu.au

David Peetz

Department of Employment Relations \&

Human Resources,

Griffith University,

170 Kessels Road QLD 4111, Australia

Tel: 0737357600

Email: d.peetz@griffith.edu.au

Glenda Strachan

Department of Employment Relations \&

Human Resources,

Griffith University,

170 Kessels Road QLD 4111, Australia

Tel: 0737355495

Email: g.strachan@griffith.edu.au
Gillian Whitehouse

School of Political and International Studies, Faculty of Humanities and Social Science,

University of Queensland,

St Lucia, QLD 4072, Australia

Tel: 0733653280

Email: g.whitehouse@uq.edu.au

Janis Bailey

Department of Employment Relations \&

Human Resources,

Griffith University,

170 Kessels Road QLD 4111, Australia

Tel: 0755527748

Email: j.bailey@griffith.edu.au

Kaye Broadbent

Department of Employment Relations \&

Human Resources,

Griffith University,

170 Kessels Road QLD 4111, Australia

Tel: 0737356566

Email: k.broadbent@griffth.edu.au 


\section{Self-Reported Harassment and Bullying in Australian Universities: Explaining differences between Regional, Metropolitan and Elite Institutions}

\section{Introduction}

Regional universities operate in a very different context to metropolitan universities. Non-metropolitan labour markets - outside of mining regions - tend to have limited job opportunities and often experience declining employment, especially those away from coastal districts, such that 'the key beneficiaries of a prolonged period of economic growth have been major metropolitan areas while other regions have had declining growth' (Cook et al., 2008, p.33). Women in particular have poorer employment prospects in regional areas (Strachan, Sullivan \& Burgess, 2002). In towns or small cities where regional universities are located, they are one of the largest employers - sometimes the largest employer - so alternative employment prospects are low. This is especially the case for academics, whereas for general or professional staff in regional universities there are at least other industries offering work for people with financial, administrative, computer or even library skills. As well, regional universities tend to have lower levels of resources than their metropolitan counterparts, especially the older ones, and therefore less capacity to provide various forms of support for staff.

This combination of contextual and organisational factors - which would lead to considerable competition for limited resources, limited capacity for organisational amelioration and limited exit options for targets of harassment - creates an environment that may be conducive to harassment if the existing literature on the topic is to be followed. Harassment is potentially expensive to organisations, yet harassment in universities has been subjected to only limited examination, and even less so in the regional dimension. This article therefore seeks to address:

- if harassment or bullying more common in regional universities than in metropolitan universities

- the extent can we identify factors that account for any regional -metropolitan differences in harassment rates?

To understand what factors, if any, may explain any differences in harassment rates, we first consider the literature, showing how the above factors, and some not yet mentioned, are said to relate to harassment. This will help us formulate specific hypotheses for testing in the large dataset that we have used, when we seek to understand whether and how geography influences harassment in universities.

\section{The literature}

Bullying, stress and violence are common hazards in Australian workplaces (Safe Work Australia, 2011). There is no widely accepted definition of bullying and its relationship to harassment, but both 'concern unwanted behaviour which causes offence to the targeted individual and which is not justified by the working or professional relationship (Simpson \& Cohen, 2004, p.164). Both are 'likely to involve the abuse of power' with sexual harassment based on gendered power. Research has tended to locate bullying behaviour within organisational power (Simpson \& Cohen, 2004, p.165). For the purposes of this article, we treat bullying and harassment as synonymous and use the terms interchangeably, partly because the distinctions in the literature are unclear, partly because we discern even less 
distinction in the popular understanding, and partly because the survey instrument we rely on for this survey also makes no distinction, asking participants questions about 'any kind of harassment or bullying at work'.

The most obvious consequences of workplace bullying are those that affect the individual victim. Workplace bullying has adverse effects on both physical and emotional well-being (Bartlett \& Bartlett, 2011; Moayed et al., 2006; Bowling \& Beehr, 2006; Salin, 2003). Impacts on physical health range from headaches and increased use of cigarettes and alcohol, through to cardiovascular and other chronic diseases. Impacts on emotional well-being ranges from reduced quality of sleep, burn out and stress, through to anxiety and depression and possibly post-traumatic stress and suicide (Bartlett \& Bartlett, 2011; Moayed et al., 2006; Bowling \& Beehr, 2006; Salin, 2003).

These health impacts would then be expected to result in increased absenteeism, lower job satisfaction and lower morale. These have organisation-related effects, with workplace bullying damaging productivity and reputation. The diverse range of costs organisations incur can include lost productivity, the cost of replacement workers when victims are absent; recruitment costs resulting from higher staff turnover; the costs of processing formal complaints; and lost business due to reputation loss (Bartlett \& Bartlett, 2011; Moayed et al., 2006; Salin, 2003). It is estimated that workplace bullying costs Australia between \$6 billion and \$36 billion every year (Productivity Commission, 2010), although this wide range reflects the lack of available reliable data.

In the educational sector Lewis (1999) reported on a survey where 18 per cent of respondents said they had had directly suffered bullying and 22 per cent reported witnessing bullying in the higher education workplace. Other single university studies have provided evidence of the prevalence of bullying and harassment. Simpson and Cohen (2004) in their study of a UK university found that just over a quarter of the sample had experienced bullying with a significantly higher proportion of women (28.4 per cent) than men (19.8 per cent). Over two-thirds of the women reported witnessing bullying compared with over a quarter of the men and the most common forms of bullying were unfair criticism, intimidation and humiliation with a resultant loss of confidence, anxiety and loss of self-esteem (Simpson \& Cohen 2004, p.170). In one university in the USA a survey of female staff reported that 43 per cent of administrators and 22 per cent of academic staff had experienced sexual harassment while employed in this university (Kelley \& Parsons, 2000).

Salin (2003) proposed a model to explain bullying that consisted of motivating structures and processes (internal competition, reward systems, difficulties laying off employees), precipitating processes (restructuring/crises, changes in management and composition of workgroup) and enabling structures/processes (power imbalances, low costs, dissatisfaction). Of particular note is that Salin theorised that in the context of high internal competition, a politicised climate and reward or remuneration systems based on relative ranking of employees, then bullying may optimise an individual's prospects. Further, Salin suggests, in these contexts bullying may be used to discipline colleagues whose performance may ultimately raise productivity hurdles. 
Bowling and Beehr (2006) undertook a systematic review, accompanied by a metaanalysis of workplace harassment. Their theoretical model of workplace harassment was based on concepts of reciprocity and attribution theory. Their model echoes Salin's ideas that the organisational climate can contribute directly and indirectly to harassment through the way that human resource systems reward perpetrators for their actions, especially where the organisational climate fosters stress and competition. Bowling and Beehr (2006) replicated a review undertaken by Moayed et al. (2006) on the importance of perceived job control. Their meta-analysis of 90 studies supported some aspects of their model, with workplace harassment more likely to be found where respondents reported high role conflict, role ambiguity, role overload, work constraints and low autonomy.

Hershcovis et al. (2007) followed Bowling and Beehr's work with a further metaanalysis of predictors of workplace aggression. In their meta-analysis they focused on organisational and interpersonal aggression as two distinct phenomena, and postulated different predictors of these two types of aggression. Interpersonal aggression was largely thought to be a function of interpersonal conflict, distributive injustice and individual victim and perpetrator characteristics. Organisational aggression was postulated to be largely a function of situational constraints, job dissatisfaction and procedural injustice. The results of their analysis of 57 studies largely supported their model, with the exception of the role of distributive or procedural injustice. Situational constraints were a robust predictor of organisational aggression. They saw situational constraints as workplace stressors that interfered with an individual's task performance or goals at work, such as the availability of resources. Taken together, these reviews and meta-analyses suggested that environments with restricted opportunities, high internal competition and low autonomy and or high role conflict are associated with higher rates of bullying.

In this context it is worth noting that universities are institutions with high levels of internal competition for resources, have a highly political climate and have reward/remuneration systems based on the relative ranking of employees. Added to this, regional universities are relatively isolated, are often a main provider of employment in the region, and thus have restricted opportunities and high internal competition, especially for academic staff. It might be expected that these universities see higher rates of bullying and harassment than their metropolitan counterparts. Therefore, this study sought to determine:

a) whether harassment is more common among staff in regional universities than other universities, and whether this is apparent across both academic and general/professional staff;

b) the extent to which demographic or workplace factors explain harassment or explain any differences in rates of harassment between regional and other universities;

c) whether there are differences between regional and other universities in the situational constraints or autonomy for staff;

d) the extent to which the measures of situational constraints or autonomy discussed above, explain harassment or account for any differences in rates of harassment between regional and other universities. 


\section{Method}

\section{Data Collection Procedure}

The data for this article come from the Work and Careers in Australian Universities Survey (Strachan et al, 2012). Following a pilot in another university, and after obtaining ethics approval from all the relevant institutional committees, several universities were approached to participate in the study, with 19 (approximately half of the sector) agreeing. One of the universities chose to survey only their sessional employees, and thus has not been included in this analysis. Those institutions agreeing to participate gave the administering institution a data file containing contact details of employees for each of three staff groups to be surveyed. This resulted in a total of 80,868 university employees: 24,165 academic staff (30 per cent), 32,983 professional/general staff (41 per cent) and 23,720 sessional staff (29 per cent).

From this population, a 'target' sample of 250 employees was randomly selected from each of the professional/general and the academic staff groups, at each participating institution. These groups of 'target' respondents were sent a hard copy survey as well as an invitation to complete the survey online and given reminders. The remainder of each sample - those outside the 'target' groups - just received the two email reminders to participate. Data collection began in August 2011 and was completed by the end of January 2012.

From the total sample of 80,868 employees, 23,869 people responded, of which 1875 (2.3 per cent) were incomplete and excluded from subsequent analysis. The final respondent sample numbered 21,994 , a 27 per cent response rate. We know of no other survey of university staff with a larger sample. There was variability in the response rate between staff groups, with 35 per cent of academic and 32 per cent of professional staff completing surveys.

\section{Survey Instrument}

The survey instruments were designed to collect information covering demographics, education, job details, income, working hours, satisfaction and security, career history, promotion, work and family issues and retirement income.

The survey instruments were tailored for the different professional and academic staff groups with substantial content replicated across the instruments. Those items that were included in both academic and general/professional surveys were reviewed and selected for inclusion in this analysis, based on the previous literature identifying variables likely to be associated with harassment and bullying in the work place.

The primary dependent variables were two items asking for participants to report their experience of harassment in the past five years. The first asked whether the individual had experienced any kind of harassment or bullying at work in the last five years, with a simple dichotomous yes or no response option. We refer to this as 
measuring 'any harassment'. If individuals responded yes to this item, they were directed to a follow-up question that asked whether they had taken or seriously considered taking a formal case in relation to harassment or bullying at work. We refer to an affirmative answer to this as signifying 'serious harassment'. (While reasons other than lack of seriousness may be behind people's decision not to proceed with a complaint, the question refers to whether respondents 'seriously considered' a formal case, and on balance this is the best proxy in the survey for the severity of harassment.)

One item in the section on job satisfaction and security asked about perceived job control ('I have a lot of input into the changes that affect me'); the format for responses contained five options, ranging from 'strongly disagree', to 'strongly agree'. A second item in the same section asked about change in the level of input staff felt they had ('To what extent have each of the following gone up or down': 'The level of input into changes that affect me'), with a three-option response format ('gone up', 'same', 'gone down'). These two items were therefore included as measures of perceived job control/autonomy.

In the career support and difficulties section of the survey, seven items were preceded by the question 'to what extent have the following helped you in advancing your career, or been a problem holding you back'. The seven items, which examined various formal and informal aspects of organisational culture, used a five-option format for responses, ranging from 'a major problem' to 'a great help'. These were subjected to exploratory factor analysis to reduce the number of inferential tests being conducted, and thus reduce type 1 errors. Analysis was conducted using principal-components analyses with an oblique rotation, with inspection of the scree plot (identifying the point of inflection) used to determine number of factors (the Eigen value criteria being inappropriate for large sample sizes). This provided a three factor solution with all items loading $>0.4$ on only one factor. Thus three items related to professional development within the university, two items possibly related to attitudes towards family responsibilities (attitude towards people of my gender, and those with family responsibilities), and two items related to more generic or age/ethnicity prejudice (attitude towards my age and my ethnicity). These scales show suitable internal consistency with a Cronbach's alpha of 0.85 for the professional development scale, and the other item pairs correlated 0.58 and 0.59 respectively. Therefore, scale scores were calculated for these three factors by summing the responses for each item.

A range of demographic variables (e.g. gender, age, ethnicity, partner, dependent children, highest qualification) and employment variables (duration at university, appointment process, type of contract, probation) were collected in both staff surveys.

\section{Analysis}

Upon receipt of de-identified data files, all data relating to items not to be included in the survey were deleted. The remaining items were then screened in both data sets and checked to ensure they had identical formats. Thereafter, the data sets were merged, using IBM SPSS Statistics v19, and screened for anomalies. 
Simple comparisons between groups were undertaken with appropriate inferential statistics using Analysis of Variance for data assumed to be parametric, or using Mann-Whitney $\mathrm{U}$ for two group comparisons, and Kruskal-Wallis $\mathrm{H}$ for multiple group comparisons of non-parametric items. All follow-up post hoc tests used a Bonferroni correction where appropriate. Where categorical data was analysed, the data distribution for one group was determined, and this was used as the expected distribution for the comparison group in the Chi-? Square inferential tests, to reduce the chance of type 1 errors resulting from the use of Chi-Square in large sample sizes.

To determine the predictive value of variables in explaining differences in reports of harassment, binary logistic regression was undertaken. The two items bullying and harassment were not merged to generate a three point scale, due to discrepancies in responding. That is 12 per cent of individuals who replied NO to any bullying, replied YES to serious bullying. When entering multiple variables together, a forward conditional analysis was used, with criteria for entry being $p<.05$, and $p<.10$ for removal, with a constant retained in the model.

The universities based in state capitals were split into the elite 'Group of Eight' (Go8) and 'Metropolitan' institutions to reflect the different funding models and histories of these institutions. This distinction between Go8 and other metropolitan universities was done as we hypothesised there would be distinct organisational cultures and internal competition which would be distinctly different given the heritage of these institutions. Thus for the rest of this article the terms 'Metropolitan' and 'Go8' universities have been taken to be mutually exclusive.

Of the universities participating in the academic staff survey, one university had multiple campuses across multiple states, and was thus excluded from the data set, due to the potential for distinct campus cultures. Two other universities had both a major metropolitan and a major regional campus along with minor regional campuses. These were also excluded. This left 15 participating universities, of which five were Go8 universities, six were Metropolitan universities based on a single major campus in a state capital and four Regional universities, with their main campus based in a city of fewer than 200,000 people. This left a final sample of 7,569 academic staff.

\section{Results}

Was harassment more common among academic and professional staff in regional universities than other universities?

Table 1 provides details of harassment rates reported amongst academics and professional staff by university status. Among academics, $24 \%$ of Go8 staff reported harassment, compared to $32 \%$ of Metropolitan staff $(x 2=87.93 ; p<.001)$, with $37 \%$ of Regional academic staff reporting harassment $(X 2=5.46 ; p=.019)$. The same pattern of results is seen for serious harassment with Go8 staff reporting least frequent harassment, followed by Metropolitan staff, with Regional staff reporting harassment most commonly $(x 2=86.63 ; p<.001)$. 
However, amongst professional staff, there were no significant differences in the number of individuals reporting harassment between Regional universities (33\%), Metropolitan (33\%) and Go8 (31\%), or reporting serious harassment (Regional 13\%, Metropolitan 12\%, Go8 11\%)

Table 1. Rates of Reported Harassment and Serious Harassment by Staff and University Type

\begin{tabular}{|l|c|c|c|c|}
\hline & \multicolumn{2}{|c|}{ Academics } & \multicolumn{2}{c|}{$\begin{array}{c}\text { Professional / } \\
\text { General }\end{array}$} \\
\hline & Any & Serious & Any & Serious \\
\hline Group of 8 & $\mathbf{2 4 \%}$ & $\mathbf{1 0 \%}$ & $\mathbf{3 1 \%}$ & $\mathbf{1 1 \%}$ \\
\hline University 1 & $25 \%$ & $10 \%$ & $29 \%$ & $10 \%$ \\
\hline University 2 & $24 \%$ & $11 \%$ & $22 \%$ & $11 \%$ \\
\hline University 3 & $26 \%$ & $10 \%$ & $31 \%$ & $11 \%$ \\
\hline University 4 & $23 \%$ & $8 \%$ & $31 \%$ & $13 \%$ \\
\hline University 5 & $26 \%$ & $10 \%$ & $32 \%$ & $12 \%$ \\
\hline Metropolitan Universities & $\mathbf{3 3 \%}$ & $\mathbf{1 4 \%}$ & $\mathbf{3 1 \%}$ & $\mathbf{1 2 \%}$ \\
\hline University 1 & $30 \%$ & $17 \%$ & $31 \%$ & $12 \%$ \\
\hline University 2 & $29 \%$ & $12 \%$ & $27 \%$ & $11 \%$ \\
\hline University 3 & $36 \%$ & $16 \%$ & $37 \%$ & $16 \%$ \\
\hline University 4 & $36 \%$ & $18 \%$ & $33 \%$ & $15 \%$ \\
\hline University 5 & $32 \%$ & $13 \%$ & $28 \%$ & $10 \%$ \\
\hline University 6 & $37.0 \%$ & $13.4 \%$ & $32 \%$ & $10 \%$ \\
\hline Regional Universities & $\mathbf{3 6 . 5 \%}$ & $\mathbf{1 6 . 3 \%}$ & $\mathbf{3 3 \%}$ & $\mathbf{1 3 \%}$ \\
\hline University 1 & $36.4 \%$ & $17.6 \%$ & $32 \%$ & $17 \%$ \\
\hline University 2 & $34.6 \%$ & $17.4 \%$ & $34 \%$ & $13 \%$ \\
\hline University 3 & $32.5 \%$ & $14.7 \%$ & $34 \%$ & $14 \%$ \\
\hline University 4 & $43.2 \%$ & $17.3 \%$ & $32 \%$ & $11 \%$ \\
\hline
\end{tabular}

Thus, consistent with our initial expectations - that the labour market functions quite differently for academics and for professional staff in Regional universities - it is only amongst academic staff that Regional universities demonstrate higher rates of harassment than Metropolitan and Go8 universities. Accordingly, the rest of this analysis focuses exclusively on the academic staff sample.

Were there demographic or workplace differences between Regional, Metropolitan and Go8 universities?

We can see the demographic and workplace characteristics of each university type in Table 2. It shows that academics in Regional universities were more likely to be born in Australia and speak English at home, more likely to be Indigenous, less likely to have a doctorate, and more likely to be holding a probationary position. Some other patterns were more complex. 
Table 2. Demographic and Employment Features, by University Type, Academic employees

\begin{tabular}{|l|c|c|c|}
\hline & Go8 & Metropolitan & Regional \\
\hline $\mathrm{N}$ & 4109 & 2455 & 833 \\
\hline Gender - Female \% & $50.4 \%$ & $49.0 \%$ & $49.3 \%$ \\
\hline Born in Australia \% & $55 \%$ & $55.5 \%$ & $59.2 \%$ \\
\hline Indigenous \% & $0.6 \%$ & $0.6 \%$ & $2.8 \%$ \\
\hline English Home \% & $79.5 \%$ & $81.4 \%$ & $84.5 \%$ \\
\hline Age - Mean (SD) & $44.9(10.8)$ & $47.7(10.5)$ & $49.0(10.3)$ \\
\hline Current Partner \% & $81.7 \%$ & $81.8 \%$ & $79.6 \%$ \\
\hline Partner Unemployed & $17 \%$ & $18.3 \%$ & $16.5 \%$ \\
\hline Children at home \% & $41.4 \%$ & $39.8 \%$ & $39.4 \%$ \\
\hline Have PhD \% & $86.1 \%$ & $79.0 \%$ & $68.7 \%$ \\
\hline Full-Time \% & $80.9 \%$ & $87.0 \%$ & $87.0 \%$ \\
\hline Fixed Term \% & $58.7 \%$ & $32.0 \%$ & $31.0 \%$ \\
\hline On Probation \% & $9.8 \%$ & $13.7 \%$ & $19.2 \%$ \\
\hline Years at University & $7.5(7.7)$ & $8.3(7.6)$ & $7.6(7.3)$ \\
\hline Union Member \% & $26.8 \%$ & $43.8 \%$ & $38.3 \%$ \\
\hline
\end{tabular}

To go into detail: there were no differences in gender distribution across university types. Go8 staff were significantly younger than Metropolitan, and Metropolitan staff were in turn younger than Regional staff $(F=87.46$; $d f=2 ; p<.001)$. More Regional academic staff were born in Australia $(x 2=5.69 ; p=.017)$ than in Metropolitan or Go8 institutions. More academic $(x 2=62.68 ; p<.001)$ staff in Regional universities were Indigenous, than in Metropolitan or Go8 universities. Fewer academic staff in Regional universities spoke a language other than English at home in Go8 $(x 2=12.85 ; p<.001)$ than in Metropolitan universities $(x 2=5.38 ; p<.020)$, who also had fewer staff not speaking English at home than Go8 universities $(x 2=5.32 ; p=.021)$. Go8 academic staff were more likely to have a $\mathrm{PhD}$ than metropolitan $(x 2=27.53$; $p<.001)$ and Regional universities $((x 2=130.37 ; p<.001)$.

Academic staff from Regional universities had been working in the institution for significantly shorter periods than in Metropolitan universities $(F=4.08 ; p=.017)$. Both Metropolitan and Regional universities had substantially fewer staff on fixed term contracts $(x 2=720.77 ; p<.001)$ than the Go8 universities, reflecting the high number of externally funded and temporary science research projects in the Go8 universities and those projects' reliance on staff on fixed-term contracts. Conversely,

Metropolitan universities have more staff on probation than Go8 ( $x 2=41.851 ; p<.001)$ with Regional universities having even more staff on probation $(x 250.26 ; p<.001)$.

More academic staff in Metropolitan universities were union members than at Go8 $(x 2=340.99 ; p<.001)$ and at Regional universities ( $x 2=9.80 ; p-.002)$, with more staff at Regional universities holding membership than at Go8( $x 2=53.41 ; p<.001)$. Go8 universities were the least likely to use a competitive appointment process (53.3 per cent), followed by Metropolitan universities (57.2 per cent) and Regional universities (6 per cent; $x 2=42.94 ; p<.001$ ).

Were there differences between Regional, Metropolitan and G08universities in autonomy and control by academic staff? 
Two items concerning an individual's perception of their input into changes that affect them and how this level of input has changed over time were examined for relationships with harassment and university type. The results are shown in Table 3. Mann Whitney tests of significance indicates that those who reported harassment, report less input into changes $(U=3619243 ; p<.001)$ and a reduction in the level of input over the previous two years $(U=3767501 ; p<.001)$. Further, using Kruskal Wallis tests we also found significant differences between university types for these items. Post hoc analysis indicates that Regional and Metropolitan universities report less input into changes that affect them than $\mathrm{Go8}$ universities $(\mathrm{KW}=39.1$; $\mathrm{df}=2$; $\mathrm{p}<.005)$ and Metropolitan and Regional universities are also more likely to report reductions in staff input over the past two years $(\mathrm{KS}=85.1$; df $=2 ; p<.005)$.

Table 3. Percentage of Respondents Indicating Agreement on Perceived Input into Changes and Reduction in Input by Experience of Harassment and University Type, Academic staff

\begin{tabular}{|l|l|l|l|l|}
\hline \multirow{2}{*}{$\begin{array}{l}\text { I have a lot of input into } \\
\text { changes that affect me }\end{array}$} & Harassment & Go8 & Metro & Regional \\
\cline { 2 - 5 } & All Strongly or Somewhat Disagreeing \\
\cline { 2 - 5 } & Yes & $55.2 \%$ & $62.9 \%$ & $57.1 \%$ \\
\cline { 2 - 5 } & No & $58.2 \%$ & $63.4 \%$ & $51.0 \%$ \\
\hline \multirow{3}{*}{$\begin{array}{l}\text { The level of input into } \\
\text { changes that affect me }\end{array}$} & \multicolumn{4}{|c|}{ \% Gone Down } \\
\cline { 2 - 5 } & All & $34.0 \%$ & $47.9 \%$ & $43 \%$ \\
\cline { 2 - 5 } & Yes & $36.0 \%$ & $48.9 \%$ & $42.5 \%$ \\
\cline { 2 - 5 } & No & $32.5 \%$ & $47.2 \%$ & $43.3 \%$ \\
\hline
\end{tabular}

Were there differences between Regional and Metropolitan and Go8 universities in career support and difficulties for academic staff?

All three scales on career support and difficulties showed significant differences associated with harassment - for each scale, lower support was perceived in Regional universities, and for each scale, respondents reporting harassment also reported lower support than those who did not report harassment (Table 4). For the items relating for professional development support $(F=501 ; \mathrm{df}=1 ; \mathrm{p}<.001)$, attitudes towards family life environment $(F=230 ; d f=1 ; p<.001)$ and general prejudice environment $(F=220 ; d f=1 ; p<.001)$, the effects were consistent within each university type. There was also a significant difference in support for professional development between university type $(F=13.14 ; \mathrm{df}=1 ; \mathrm{p}<.001)$, but not for attitudes towards family or general prejudice. Regional academic staff reported less support for professional development than either Metropolitan or Go8 universities $(p<.001)$, but there were no differences between these university types. 
Table 4. Mean and Standard Deviation for Attitudinal Measure of Career Support and Difficulties by Harassment and University Type, Academic employees

\begin{tabular}{|l|l|c|c|c|c|c|c|}
\hline & & \multicolumn{2}{|c|}{$\begin{array}{c}\text { Professional } \\
\text { Development }\end{array}$} & \multicolumn{2}{c|}{$\begin{array}{c}\text { Attitude } \\
\text { Family }\end{array}$} & \multicolumn{2}{c|}{$\begin{array}{c}\text { Age/ethnicity } \\
\text { Prejudice }\end{array}$} \\
\hline $\begin{array}{l}\text { University } \\
\text { Type }\end{array}$ & $\begin{array}{c}\text { Experienced } \\
\text { harassment }\end{array}$ & Mean & SD & Mean & SD & Mean & SD \\
\hline Go8 & No & 10.43 & 2.7 & 6.04 & 1.1 & 6.19 & 1.1 \\
\cline { 2 - 8 } & Yes & 8.62 & 3.3 & 5.46 & 1.4 & 5.74 & 1.1 \\
\cline { 2 - 8 } & Total & $\mathbf{9 . 9 4}$ & $\mathbf{2 . 9}$ & $\mathbf{5 . 8 9}$ & $\mathbf{1 . 2}$ & $\mathbf{6 . 0 7}$ & $\mathbf{1 . 1}$ \\
\hline \multirow{4}{*}{ Metro } & No & 10.36 & 2.6 & 6.15 & 1.2 & 6.21 & 1.1 \\
\cline { 2 - 8 } & Yes & 8.55 & 3.2 & 5.61 & 1.4 & 5.61 & 1.2 \\
\cline { 2 - 8 } & Total & $\mathbf{9 . 7 4}$ & $\mathbf{2 . 9 9}$ & $\mathbf{5 . 9 6}$ & $\mathbf{1 . 3}$ & $\mathbf{6 . 0 0}$ & $\mathbf{1 . 2}$ \\
\hline \multirow{3}{*}{ Regional } & No & 10.20 & 2.9 & 6.13 & 1.2 & 6.20 & 1.2 \\
\cline { 2 - 8 } & Yes & 7.81 & 3.3 & 5.34 & 1.3 & 5.58 & 1.2 \\
\cline { 2 - 8 } & Total & $\mathbf{9 . 2 6}$ & $\mathbf{3 . 3}$ & $\mathbf{5 . 8 3}$ & $\mathbf{1 . 3}$ & $\mathbf{5 . 9 7}$ & $\mathbf{1 . 2}$ \\
\hline
\end{tabular}

Note: Higher mean scores signify greater support; lower mean scores signify greater difficulties.

To what extent do these factors account for differences in rates of harassment between Regional and other universities?

Binary logistic regression was undertaken to determine which factors were predictive of reported bullying, and to what extent they may be explained by differences between university types. This analysis was taken using a step wise approach, with conditional entry being applied within each step. University type was entered on step one of the logistic regression, as this was a factor we wish to account for differences in. On step 2 all demographic characteristics that showed Regional effects for academic staff were entered stepwise. On step 3 all workplace characteristics that showed Regional effects were entered stepwise. On step 4, the two items related on perceived input into job were entered stepwise. Finally on step 5 the three factors on prejudice and development were, with the two prejudice scores entered first followed by the professional development scale. The results of this regression can be seen in Table 5.

Although several demographic (Indigenous, speaking English at home, age) and workplace characteristics (length of current employment, union membership, continuing position and appointment) are predictive of reported bullying, they do not seem to account for regional differences, as the size of the effect for regionality is not significantly impacted by the addition of these variables to the model. Further, 'less perceived input' and 'reductions in perceived input' into job changes are both predictive of reported bullying, but similarly did not account for regional differences.

Both family attitude and general prejudice were predictive of harassment, and the relationship between competitive appointment process and harassment was no longer significant when these variables were entered into the regression.

The addition of the professional development support scale to the model reduced the predictive value of university type substantially, with the coefficient falling by more than half, although it remained significant as a predictor of harassment. A Sobel test 
was run, using raw regression coefficients (run separately) which demonstrated that professional development support was partially mediating the relationship between university type and levels of reported harassment ( $S=20.37$; SE $=0.00$ ).

Notably, the addition of professional development support also resulted in the item on changes in perceived input no longer being predictive of reported harassment (although the perceived level of input remained significant).

In a separate analysis, support for professional development also partially mediated the variance in individual university rates of harassment. That is, differences between universities and university types in reported harassment were at least partly a function of the degree of perceived academic professional development support within the institution. 
Table 5. Results of Multiple Logistic Regression to Predict Harassment Controlling for Sample Characteristics.

\begin{tabular}{|c|c|c|c|c|c|c|c|}
\hline & & \multicolumn{3}{|c|}{ Harassment } & \multicolumn{3}{|c|}{ Serious Harassment } \\
\hline & & $\mathrm{B}$ & Wald & Sig. & $\mathrm{B}$ & Wald & Sig. \\
\hline \multicolumn{8}{|c|}{ Step 1 University Type } \\
\hline & Regional University & .33 & 72.06 & .001 & & & \\
\hline \multicolumn{8}{|c|}{ Step 2 Demographic Variables } \\
\hline & Indigenous & -.37 & 16.12 & .001 & & & \\
\hline & $\begin{array}{l}\text { English spoken at } \\
\text { home }\end{array}$ & .37 & 18.37 & .001 & & & \\
\hline & Age & .01 & 28.12 & .001 & & & \\
\hline \multicolumn{8}{|c|}{ Step 3 Workplace Variables } \\
\hline & $\begin{array}{l}\text { Fixed Term } \\
\text { Contract }\end{array}$ & -.27 & 16.69 & .001 & & & \\
\hline & Years at Institution & -.02 & 13.08 & .001 & & & \\
\hline & Union Member & .57 & 83.29 & .001 & & & \\
\hline & $\begin{array}{l}\text { Competitive } \\
\text { Appointment }\end{array}$ & -.13 & 12.92 & .001 & & & \\
\hline \multicolumn{8}{|c|}{ Step 4 Perceived Input to Job } \\
\hline & Lot of input & -.27 & 130.77 & .001 & & & \\
\hline & Changed Input & -16 & 12.46 & .001 & & & \\
\hline \multicolumn{8}{|c|}{ Step 5 Perceived Prejudice and Development Support } \\
\hline & Regional University & .12 & 4.22 & .040 & .19 & 7.20 & .007 \\
\hline & Indigenous & -.40 & 8.41 & .004 & -.36 & 7.05 & .008 \\
\hline & Age & .10 & 4.15 & .042 & .02 & 9.43 & .002 \\
\hline & $\begin{array}{l}\text { English spoken at } \\
\text { home }\end{array}$ & .29 & 5.13 & .023 & & & \\
\hline & $\begin{array}{l}\text { Fixed Term } \\
\text { Contract }\end{array}$ & .37 & 15.10 & .001 & & & \\
\hline & Years at Institution & -.03 & 20.02 & .001 & -.03 & 13.26 & .001 \\
\hline & Union Member & .40 & 20.76 & .001 & .51 & 21.43 & .001 \\
\hline & $\begin{array}{l}\text { Competitive } \\
\text { Appointment }\end{array}$ & -.06 & 1.11 & .292 & -.15 & 4.89 & .027 \\
\hline & Lot of input & -.13 & 14.23 & .001 & -.12 & 9.83 & .002 \\
\hline & Changed Input & .08 & 1.63 & .202 & & & \\
\hline & $\begin{array}{l}\text { Development } \\
\text { Support }\end{array}$ & -.14 & 79.28 & .001 & -.13 & 45.52 & .001 \\
\hline & Family Attitude & -.17 & 14.63 & .001 & -.19 & 12.22 & .001 \\
\hline & General Prejudice & -.24 & 24.07 & .001 & -.15 & 6.98 & .008 \\
\hline
\end{tabular}

Is serious harassment explained in similar ways?

The analysis so far has focused on individuals reporting any kind of harassment or bullying in the work place. Then the regression analysis was replicated with reporting of serious bullying as the dependent variable, dichotomously coded as reported serious harassment or not. The results of this analysis largely replicate that for any harassment. As shown in Table 5 the main difference is that the effect of university type was not explained by differences in perceived professional development support when looking at the more serious level of harassment or bullying. In 
addition, speaking English at home was not significant in explaining serious harassment, and nor was being on a fixed term contact.

\section{Discussion and conclusions}

The analysis reported here highlights several key points. First, while general/professional staff showed no difference in harassment rates between regional and non-regional universities, academic staff at regional universities reported significantly higher harassment. This probably reflected the labour market and resource context of regional universities. The labour markets in which they are situated tend to have limited job opportunities and often experience declining employment, and alternative employment prospects for employees of regional universities - especially academics - are low. Regional universities also tend to have fewer resources than Metropolitan and Go8 institutions, and therefore less capacity to provide various forms of support for staff.

Second, consistent with these resource constraints, academic staff in regional universities report less support for professional development than staff in Metropolitan based universities. Third, these differences in support for professional development partially mediate differences between university types.

Fourth, markers of prejudice were predictive of reported harassment, such that more perceived negative attitudes towards family commitments, more perceived negative general prejudice and being an Aboriginal Australian was associated with increased reporting of harassment. As the regional universities in this study employ more Aboriginal Australians it is likely that this issue is also contributing to the increased reporting of harassment in regional universities, although the contribution is probably small due to their low overall numbers in the university workforce.

People in a continuing position, working at the university longer, being older and not feeling that they have much input into changes, are more likely to report being harassed or bullied over the previous five years. Interestingly, individuals who were appointed by a competitive process report more harassment (31 per cent) than those who were appointed without any competitive appointment process (22 per cent), though in regressions the significance of this factor varied between equations.

Despite the large sample size and representation from a number of universities, these results must be treated with some caution. The main caveat is that the primary measures of interest are single items. There was no definition of harassment or bullying provided, which meant we could not ensure that these items were being interpreted consistently, or in line with legislative or research definitions (though these vary as well). As mentioned, the questionnaire did not attempt to distinguish between harassment and bullying.

There is also the question of potential reverse causality. Variables used to predict harassment, such as lack of professional development support, and lack of input into changes may also be consequences of harassment. However, the fact that there are specific effects in the data, such as regional differences for professional development support but not for other negative attitudes, would suggest that these 
analyses are not just reflecting overlapping measurement issues. Reverse causality probably also affects the unionisation question: it is likely that experiencing harassment and bullying would lead someone to join a union, so we cannot be confident that union membership results in harassment. While some unionists may be victimised for being unionists, the evidence of this occurring is mostly from outside the university sector.

The bulk of items in the survey analysed have a five year time frame, but 46 per cent of academics in the sample had worked in their current institution for less than five years. It is not possible to be certain that participants' responses are wholly a function of their current institutional experience, adding some noise to the data. In addition, there is the problem inherent in making any causal attributions from crosssection surveys. We do not consider gender here, because it plays no role in explaining regional/non-regional differences, and is a large enough topic to be covered in its own right.

Despite the above limitations, our findings align with the wider literature on harassment and bullying. Firstly, the effect of perceived input into decision making was highlighted by reviewers of the literature in the context of job control, autonomy and role conflict (Mayed et al., 2006, Bowling \& Beehr, 2006, Hershcovis et al., 2007). Given the value that academic staff attach to autonomy, it is no surprise that this is highlighted as a key issue in this study. The measures of perceived input into changes, perceived reduction in input, attitudes towards family commitments, general prejudice and professional development support are all heavily intercorrelated both in the sample as a whole, and when examined for each institution separately $(0.17<r<0.48)$. Thus it may be that it is the wider organisational culture that nurtures harassment and bullying, rather than any specific issues, replicating the results of other reviews and meta-analyses (Salin, 2003, Mayed et al., 2006, Bowling \& Beehr, 2006, Hershcovis et al., 2007).

Our results shed some interesting light on the regional differences in reported harassment seen in the data. The fact that support for professional development is both a robust predictor of reported harassment and partially mediates the effect of regionality on reported harassment also points to the role of competition for resources. This is consistent with the ideas raised by Salin (2003) of internal competition being a key driver of harassment and of Hershcovis et al.'s findings on the importance of situational constraints (2007). Related to this was the finding that academics appointed without a competitive process were less likely to report harassment; such processes may suggest tighter labour market conditions, with greater alternative employment opportunities for staff and less rigid competition for resources. However, such an interpretation is preliminary at best, given the way the coefficient on this variable shifted in and out of significance.

All these findings point to organisational culture, whether driven from within or from without, as important in understanding harassment and bullying in the workplace. Problems can be self-perpetuating, if a culture accepting of harassment and bullying pushes people to conform or be bullied into moving on. Culture appears to be influenced, at least in part, by the labour market and resources context of the university. Changing such a culture, even with a determined cross-organisation effort, is a long term endeavour. 


\section{References}

Bartlett, J.E., \& Bartlett, M.E. (2011). Workplace Bullying: An Integrative Literature Review. Advances in Developing Human Resources, 13: 69-84.

Bowling, N.A., \& Beehr, T.A. (2006). Workplace Harassment From the Victim's Perspective: A Theoretical Model and Meta-Analysis. Journal of Applied Psychology, 91(5), 998-1012.

Cook, B., Mitchell, W., Quirk, V. \& Watts, M. (2008). Creating effective local labour markets: a new framework for regional employment policy, Centre of Full Employment and Equity, University of Newcastle, November.

Hershcovis, M.S., Turner, N., Barling J., Arnold K.A., Dupre, K.E., Inness, M., Manon, LeBlanc, M., \& Sivanathan, N. (2007). Predicting Workplace Aggression: A MetaAnalysis. Journal of Applied Psychology, 92(1), 228-238.

Kelley, M. \& Parsons, B. (2000). Sexual Harassment in the 1990s: A University-wide Survey of female Faculty, Administrators, Staff, and Students. The Journal of Higher Education, 71(5), 548-568.

Lewis, D. (1999). Workplace bullying: Interim findings of a study in further and higher education in Wales. International Journal of Manpower, 20(1/2), 106-118.

Moayed, F.A., Daraiseh, N., Shell, R., \& Salem, S. (2006). Workplace bullying: a systematic review of risk factors and outcomes. Theoretical Issues in Ergonomics Science, 7(3), 311-327.

Productivity Commission 2010, Performance Benchmarking of Australian Business

Regulation: Occupational Health \& Safety, Research Report, Canberra. Retrieved from http://www.pc.gov.au/_data/assets/pdf_file/0007/96163/ohs-report.pdf on 10/11/2013.

Safe Work Australia. (2011). How to Manage Work Health and Safety Risks.: Code of Practice: Safe Work Australia. Retrieved from

http://www.safeworkaustralia.gov.au/sites/SWA/about/Publications/Documents/633/ How_to_Manage_Work_Health_and_Safety_Risks.pdf , on 10/11/2013.

Salin, D., (2003). Ways of Explaining Workplace Bullying: A Review of Enabling, Motivating, and Precipitating Structures and Processes in the Work Environment. Human Relations, 56(10), 1213-1232.

Simpson, R. \& Cohen, C. (2004). Dangerous Work: The Gendered Nature of Bullying in the Context of Higher Education. Gender, Work and Organization, 11(2), 163-186.

Strachan, G., Sullivan, A. \& Burgess, J., (2002). Women's Work In Regional Labour Markets: Spatial Versus Industry Differences, Labour \& Industry, 13(2), 91-116.

Strachan G., Troup C., Peetz D., Whitehouse G., Broadbent K. \& Bailey J. (2012). Work and Careers in Australian Universities: Report on Employee Survey. Centre for Work, Organisation and Wellbeing (WOW), Griffith University. Accessed at http://www.griffith.edu.au/business-government/centre-work-organisationwellbeing/research/regulation-institutions/projects/work-careers-australianuniversities on 10/11/2013. 